\title{
KREASI SULAMAN SUJI CAIA MENGGUNAKAN TEKNIK KERANCANG TIMBUL UNTUK PAKAIAN PEREMPUAN MINANGKABAU
}

\author{
Silva Yusalim, Susas Loravianti, Nursyirwan \\ Program Studi Penciptaan Seni Kriya \\ Mahasiswa Pascasarjana Institut Seni Indonesia Padangpanjang \\ Email: Silvayusalim12@gmail.com
}

\begin{abstract}
Abstrak
Penciptaan karya seni "Kreasi Sulaman Suji Caia menggunakan Teknik Kerancang Timbul untuk Pakaian Perempuan Minangkabau" merupakan kolaborasi Suji Caia dengan kerancang manual berbentuk timbul menggunakan benang emas/ perak metalik. Kreasi Sulaman Suji Caia ini di terapkan pada pakaian perempuan Minangkabau berupa kerudung, baju kurung dan tas. Bentuk karya ini merupakan hasil kreasi pengkarya dengan konsep ekspresi personal seni sebagai lambang ekspresi pribadi pengkarya terhadap Suji Caia. Kreasi ini merupakan karya seni tekstil yang diaplikasikan pada pakaian perempuan Minangkabau menggunakan motif mawar dan motif Saik Galamai. Dalam karya ini pemasangan payet, swarosvky dan jambul Kristal merupakan teknik tambahan yang dipakai untuk menambah nilai keindahan karya. Metode dalam penciptaan karya kriya seni ini melalui beberapa tahap, antaranya tahap eksplorasi, perancangan, dan perwujudan. Karya yang diciptakan berjumlah lima set pakaian perempuan minang yang dipasangkan dengan songket Pandai Sikek.
\end{abstract}

Kata Kunci: Sulaman Suji Caia; Bordir; Kerancang; Pakaian Perempuan Minangkabau

\begin{abstract}
The creation of "Suji Caia's embroidery creations using engineering techniques. Embossed for Minangkabau Women's Clothing" is a collaboration of Suji Caia with a manual draft embossed using gold / silver thread metallic. This Suji Caia embroidery creation is applied to Minangkabau women's clothing in the form of a veil, baju kurung and a bag. The form of this is the creation with the concept of expressing personal art as a symbol of the author's personal expression of Suji Caia. This creation is a work of textile art which is applied to Minangkabau women's clothing using rose and saik galamai motifs. In this work, the use of sequins, swarosvky and crystal crest are additional techniques used to add beauty value to the work.There are several stages in creating this artwork method, including exploration, design and embodiment stages. As a result, five works were created, the Minangkabau women's clothing set paired with Pandai Sikek songket.
\end{abstract}

Keywords: Suji Caia Embroidery, Embroidery, Design, Minangkabau Women's Clothing.

\section{PENDAHULUAN}

Sulaman Suji caia merupakan kerajinan tangan yang dikerjakan oleh perempuan Kotogadang. Kerajinan ini masuk ke Indonesia pada awal abad ke-18 dan berkembang hingga abad ke-20.
Sulaman Suji Caia berkembang di

Sumatera Barat semenjak adanya sekolah yang didirikan oleh Roehana Koeddoes pada tahun 1911 bernama kerajinan Amai Setia, bertempat di Kotogadang.

Sekolah tersebut mengajarkan 
bermacam-macam

keterampilan menyulam dan membordir. Sulam merupakan kerajinan menata benang dengan bermacam-macam bentuk di atas kain yang bertujuan untuk memperindah kain tersebut. Suhersono, (2004:6) mengatakan sebagai berikut.

"Bordir identik dengan menyulam, karena kata "Bordir" diambil dari istilah Inggris embroidery yang artinya sulaman merupakan salah satu kerajinan ragam hias (untuk aksesoris berbagai busana) yang menitik beratkan pada keindahan dan komposisi warna benang pada medium berbagai kain".

Sulam Suji Caia adalah menghias permukaan kain menggunakan benang dengan tingkatan gradasi warna benang yang berbeda, jika memakai satu warna benang disebut Suji. Pengerjaan Suji Caia juga bisa dikerjakan dengan bantuan mesin bordir manual yang disebut bordir Suji Caia. Secara visual hasil border Suji Caia sama seperti hasil sulam Suji Caia. Perbedaan sulaman Suji Caia dengan bordir Suji Caia yaitu dari cara pengerjaan dan kualitas Suji Caia yang dihasilkan, namun masih sama-sama disebut dengan Suji Caia.

Pengerjaan Suji Caia membutuhkan ketelitian, ketekunan dan kesabaran serta jiwa seni. Dalam proses pengerjaan Suji khas dan kerajinan yang unggul dari Caia ada yang disebut dengan Mancaia Sumatera Barat. Hasil kerajinan Suji Caia Banang, yaitu teknik dasar dari Suji Caia. dan kerancang banyak diminati oleh

Mancaia Banang merupakan menata benang di permukaan kain dengan teknik menyuji (setikan) secara berulang dan berlampis dengan beberapa warna benang yang telah dipilih. Dimulai dari warna benang yang muda ke warna benang yang tua dan sebaliknya, tergantung desain motif, sehingga pewarnaan pada Suji Caia berbentuk alami seperti warna bunga aslinya, warna tampak membaur tanpa sekatan antara warna-warna benang yang digunakan. Bentuk seperti inilah yang menjadi kelebihan dari Suji Caia.

Hasil kerajinan Suji Caia termasuk ke dalam kerajinan yang bernilai tinggi di Sumatera Barat. Tidak hanya kerajinan Suji Caia, bordir kerancang juga termasuk kerajinan yang diminati, karena pembuatannya secara manual. Bordir kerancang adalah suatu teknik menghias permukaan kain dengan cara melobangi kain, lalu merentang berbagai bentuk setikan dengan benang pada lobang tersebut, sehingga terbentuk kerancang.

Kerancang biasanya diaplikasikan pada baju kurung, baju kebaya, baju blus, baju kemeja, baju koko, jilbab, pakaian sholat dan lenan rumah tangga (bahan berupa kain yang gunakan untuk keperluan rumah tangga). Kedua teknik kerajinan ini termasuk kerajinan yang 
perempuan, yang biasanya dipakai ke kerancang benang emas/perak berbentuk acara formal dan acara ritual adat. timbul dan bertingkat. Benang emas/perak Penggemar sulaman Suji Caia tidak hanya identik dengan bentuknya yang mengkilap di Sumatera Barat, namun pendatang dari namun punya tekstur yang kasar dan luar juga menyukai hasil kerajinan ini. murah putus. Benang emas/perak seperti wisatawan dan masyarakat umum biasanya digunakan untuk melilit bagian lainnya. batang dan daun pada motif yang setelah

Adapun dari bentuk desain, Suji Caia. Dalam karya "Kreasi Sulaman pewarnaan dan motif, hasil sulaman ini Suji Caia menggunakan Teknik Kerancang belum berkembang karena desain bentuk Timbul untuk Pakaian Perempuan tidak berubah dari dahulu. Desain hanya Minangkabau” benang emas/perak memakai beberapa motif yang dipakai digunakan untuk membuat Bordir berkelanjutan, sehingga terlihat tidak kerancang yang diaplikasikan pada memiliki inovasi motif dalam pembuatan pakaian perempuan Minangkabau, berupa: produk. Penggunaan motif pada teknik kerudung, baju kurung dan tas.

Suji Caia ini cenderung memakai bunga

Karya "Kreasi Sulaman Suji Caia dengan diameter besar tanpa menggunakan Teknik Kerancang Timbul mempertimbangkan komposisi motif untuk Pakaian Perempuan Minangkabau" yang benar. Pewarnaannya identik memakai dua motif. Pertama, motif Saiak dengan warna kontras dan cerah. Galamai yang ditata pada bagian pinggir. Pemilihan warna bahan yang terlalu Motif ini menyimbolkan bahwa dalam berlawanan dengan warna benang dan suatu masalah seorang perempuan harus pola motif yang dipakai hanya berupa hati-hati dalam mengambil keputusan. pola mengisi bidang (susunan ragam hias Kedua, motif bunga mawar yang mengikuti bentuk bidang yang akan Menyimbolkan seorang perempuan harus dihias).

Perihal demikian mendasari pengkarya untuk menjadikan penciptaan seni yang berjudul "Kreasi Sulaman Suji bisa menjaga dirinya dengan baik dan seorang perempuan yang mempunyai rasa kasih sayang pada anak-anak.

Caia menggunakan Teknik Kerancang memperlihatkan kreasi Suji Caia Timbul untuk Pakaian Perempuan berbentuk timbul. Kerancang benang Minangkabau" dalam karya ini pengkarya emas/perak ditempelkan bertingkat pada mengkolaborasikan Suji Caia dengan Suji Caia, sehingga Suji Caia berbentuk 
timbul. Memakai kontras dan gradasi. Caia pada pakaian perempuan Bentuk pola hias, motif dan Minangkabau. Menghindari terjadinya penempatannya untuk pakaian kesalahan dalam penciptaan karya. Data perempuan Minangkabau mempunyai yang didapat berupa dari hasil observasi makna yang berkaitan dengan sifat-sifat dan wawancara serta dengan perempuan di Minangkabau.

Dalam memperoleh dan menerapkan pengetahuan pada konsep penciptaan karya "Kreasi Sulaman Suji Caia menggunakan Teknik Kerancang Timbul untuk Pakaian Perempuan Minangkabau” pendekatan yang dilakukan adalah pendekatan estetik yaitu mengkaji nilai-nilai keindahan seni kriya yang menyangkut motif, warna, dan ragam hiasnya.

Pengamatan yang dilakukan pengkarya dalam observasi adalah mengamati bentuk Suji Caia dan penerapannya di Kotogadang. Memperhatikan tentang bagaimana bentuk motif dan pewarnaan yang dipakai dalam proses membuat Suji Caia.

Melakukan wawancara dengan para pengrajin Sulam Suji Caia dan anggota yayasan Amai Setia (ibu Susi, 53 tahun), yang mengetahui dan mempunyai pengalam tentang Suji Caia. Wawancara juga dilakukan dengan pemangku adat yang paham tentang pakaian perempuan Minangkabau agar karya yang dibuat mempunyai referensi yang kuat. mengumpulkan data tentang bentuk, sejarah, makna dan pemakaian sulam Suji mengumpulkan beberapan buku sebagai referensi tentang Suji Caia, bordirdan pakaian perempuan Minangkabau untuk memperkuat penciptaan karya.

Kehadiran sebuah karya seni telah melalui suatu proses penciptaan yang sudah direncanakan secara matang, baik menyangkut ide, bentuk, bahan, teknis, makna, yang ingin disampaikan melalui karya seni yang diciptakan.

Metode yang digunakan sesuai dengan metode dalam buku SP Gustami (2007: 329), yaitu: (1) Eksplorasi, Tahap ekplorasi merupakan tahap pertama dalam proses penciptaan seni kriya. Pengkarya menjelajah, mengamati, merenungkan tentang apa yang akan diciptakan. Hal ini tidak lepas dari bentuk pengumpulan data pustaka maupun data yang lansung didapat dari lapangan yang dijadikan sebagai pembanding karya, serta menemukan ide dalam sebuah penciptaan sebuah karya. (2) Perancangan, merupakan pengembangan dari tahap ekplorasi, setelah di ekplorasi pengkarya melakukan eksperimen suji caia yang di ekspresikan dengan kerancang timbul dari benang emas/perak. 
(3) Tahap perwujudan merupakan lanjutan dari tahap perancangan. Pemilihan sketsa alternatif menjadi skesta terpilih yang kemudian diolah menjadi model prototipe hingga bentuk yang diinginkan.

\section{HASIL DAN PEMBAHASAN}

1) Motif

Motif adalah hiasan yang dibuat dengan tujuan menghias suatu bidang atau benda sehingga bidang atau benda tersebut menjadi lebih indah.Suhersono (2004:13) mengatakan sebagaiberikut.

Motif adalah desain yang dibuat dari bagian-bagian bentuk, berbagai macam garis atau elemen-elemen yang terkadang begitu kuat dipengaruhi oleh bentukbentuk stilisasi atau gubahan alam benda dengan gaya dan ciri khas sendiri.

Penciptaan karya dengan teknik sulam/bordir sangat dipengaruhi oleh bentuk motif. Motif merupakan faktor terpenting dalam mewujudkan suatu karya sulam/bordir yang bagus. Pembuatan desain motif yang pas akan mempengaruhi hasil dari teknik Suji Caia yang diciptakan.

Karya "Kreasi Sulaman Suji Caia menggunakan Teknik Kerancang Timbul untuk Pakaian Perempuan Minangkabau” memakai 2 motif yaitu:

a) Motif Saik Galamai
Merupakan salah satu motif dari Minangkabau yang berbentuk jajar segi empat jajar genjang. Motif Saik Galamai mempunyai makna dan simbol di Minangkabau. Mutia dkk (2012: 33) mengatakan sebagai berikut.

Galamai adalah makanan khas dari Sumatera Barat yang dibuat dari beras pulut, gula tebu dan santan. Galamai dimasak dengan cara diaduk dengan teliti agar memperoleh hasil yang baik. Setelah matang dipotong-potong berbentuk segi empat jajar genjang dan ditarok 4 potong didalam pring. Hal ini merupakan tanda selamat datang pada tamu dalam acara adat di Minangkabau. Oleh karena itu motif Saik Galamai mengambarkan seseorang yang mempunyai sifat teliti dan bijaksana."Motif Saik Galamai dalam ukiran Minangkabau mengandung makna kehati-hatian dalam berbuat dan menghadapi berbagai permasalahan supaya tidak bertambah kusut".

Dalam karya "Kreasi Sulaman Suji Caia menggunakan Teknik Kerancang Timbul untuk Pakaian Perempuan Minangkabau" motif Saik Galamai ditempatkan di pinggir kerudung. Motif Saik Galamai dalam karya ini menyimbolkan bahwa dalam suatu masalah seorang perempuan harus hatihati dan bijaksana dalam menghadapi masalah serta dalam mengambil keputusan. " Seorang perempuan haruslah 
hati-hati dalam segala perbuatan dan tingkah laku didalam dirinya." ( Hakimy Idrus, 1994: 82).

b) Motif bunga mawar

Motif bunga mawar merupakan motif dari tumbuh-tubuhan yang disebut motif naturalis. Motif Minangkabau pada umumya bersumber kepada falsafah "Alam Takambang Jadikan Guru" yang maksudnya bahwa semua isi alam dapat dijadikan contoh terutama membuat motif seperti pepatah Minang.Usria (1996:11) mengatakan.

Panakik pisau sirawik, Ambiak galah lintabuang,

Salodang ambiak ka niru,

Satitiak jadikan lauik,

Nan sakapa jadikan gunuang, Alam takambang jadikan guru.

Pepatah ini bermaksud bahwa semua yang kita lihat pada alam semesta dapat jadikan sebagai acuan. Seperti penciptaan motif bunga Mawar, pengkarya melihat dari bentuk bunga mawar yang indah, mempunyai mahkota bertingkat yang tersusun berpuntir. Bunga mawar mempunyai warna yang menarik serta aroma yang harum dan khas. Bunga mawar pada umumnya diberikan seseorang pada orang yang disayangi sehingga bunga mawar melambangkan rasa kasih sayang.
Srtuktur batang bunga mawar yang mempunyai duri yang tajam menyimbolkan cara beradaptasinya dengan lingkungan.

Dalam karya "Kreasi Sulaman Suji Caia menggunakan Teknik Kerancang Timbul untuk Pakaian Perempuan Minangkabau" motif bunga Mawar diletakan sebagai motif utama pada pakaian perempuan Minangkabau. Motif ini terletak di bagian-bagian pola hias yang telah didesain. Dalam karya ini, motif bunga mawar menyimbolkan bahwa seorang perempuanmempunyai sifat rendah hati, baik serta mempunyai rasa kasih sayang pada keluarga dan sesama manusia. Pandai menjaga diridan kehormatannya sebagai seorang paerempuan. "Padusi di Minangkabau haruslah menjadi perempuan dan menjaga martabat perempuan bukan sebaliknya" (Jamil Muhammad, 2015: 17).

\section{2)Suji Caia}

Suji Caia adalah teknik menghias permukaan kain dengan benang secara dekoratif melalui beberapa teknik tusuk loncat atau Suji. Suji Caia dilakukan dengan mengatur beberapa lampisan Suji yang searah dalam satu bidang bunga. Lampisan Suji terdiri dari beberapa warna yang diatur secara dekoratif mulai dari warna muda, warna sedang hingga warna yang tua. Lampisan warna Suji Caia 
terlihat membaur dan teratur sehingga pengantin perempuan dan laki-laki, tampak seperti warna bunga aslinya. Suji kambuik, tempat rokok dan ikat pinggang Caia adalah menyulam dengan benang marapulai, juga bisa digunakan pada sutera atau satin pada permukaan kain bagian belakang dan Baju Cino Suto dengan Suji panjang pendek bergantian, pengantin laki-laki”.

agar pencampuran benang tampak seperti bayangan tiga dimensi"(Sita,2011:24).

Penggunaan benang dalam proses Suji Caia sampai 31 warna benang. Satu motif memakai 6 sampai 8 tingkatan warna. Pewarnaan antara kuntum bunga dalam motif memakai tingkatan warna benang yang berbeda begitu pula dengan daun dan kreasi motif yang lain. Hasil pewarnaan yang cocok dan pembuatan teknik yang rapi sehingga terciptakan Suji Caia yang indah dan menarik. Oleh karena itu, warna Suji Caia terlihat kontras.

Suji Caia pada umumnya digunakan untuk menghias permukaan selendang Kotogadang, baju kurung, baju kebaya serta lenan rumah tangga. Kerajinan Suji Caia ini biasa dibeli dengan harga yang tinggi. Di daerah Kotogadang Suji Caia pada umunya di aplikasikan pada pakaian adat. Sita (2011:27) mengatakan sebgai berikut.

Suji Caia biasanya digunakan antara lain untuk desain Selendang Gadang (selendang kebesaran),Undok (kerudung), yang digunakan pada pakaian pengatin perempuan dengan baju Suto Terawang Duo dan Terawang Tigo, selop
Karya "Kreasi Sulaman Suji Caia menggunakan Teknik Kerancang Timbul untuk Pakaian Perempuan Minangkabau” mengkreasikan Suji Caia dengan tambahan bordir kerancang manual memakai benang emas/perak. Suji Caia yang ditambah dengan satu tingkat Suji Caia dan satu tingkat bordir kerancang benang emas/perak. Sehingga motif Suji Caia berbentuk timbul.

3) Pakaian perempuan Minangkabau

Pakaian adalah bahan tekstil yang menutupi tubuh manusia untuk berlindung dari hujan dan panas matahari. Pakaian perempan di Minangkabau terdiri dari pakaian muslim berupa stelan baju kurung dalam dengan rok (kodek) dan memakai kerudung sebagai penutup kepala. Ketika berpergian perempuan Minangkabau memakai kampia (tas) untuk meletakkan barang bawaannya.

Perempuan dan wanita merupakan jenis panggilan yang sama di Minangkabau namun, mempunyai makna yang berbeda. Jamil Muhammad (2015:42) mengatakan sebagai berikut.

Wanita dan perempuan berbeda artinya dalam istilah di Minangkabau. Kedua panggilan itu adalah Padusi. Untuk 
menyebut seorang wanita dan perempuan di Minangkabau adalah padusi. Namun pengertian perempuan secara istilah akan berbeda. Sebutan perempuan bila wanita di Minangkabau setelah ia memakai sifat yang digariskan oleh adat. Adapun yang disebut perempuan dalam istilah padusi di Minangkabau yakni yang mempunyai sifat terpuji, baik budi pekerti, tingkah laku, kecakapan, kemampuan dan ilmu pengetahuannya.

\section{Pakaian}

perempuan

di

Minangkabau merupakan pakaian yang sesuai kaidah agama dan sopan. Dalam karya ini pakaian perempuan yang dimaksud terdiri dari: kerudung, baju kurung dan tas.

a) Kerudung

Kerudung adalah kain berbentuk selendang yang digunakan untuk menutup kepala seorang perempuan di Minangkabau. Dalam karya ini pengkarya membuat kerudung yang dihiasi oleh kreasi sulam Suji Caia menggunakan teknik kerancang timbul dari benang emas/perak. Kreasi Suji Caia ditata dalam bentuk berbagai pola hias. Ditambah dengan tempelan payet, batu kristal dan swarovsky.

\section{b) Baju Kurung}

Baju kurung adalah baju yang mengurung badan, tanpa memperlihatkan bentuk tubuh, berukuran panjang hingga lutut dan longgar. Baju kurung yang dipakai oleh perempuan melambangkan bahwa seorang perempuan terkurung oleh undangundang yang sesuai dengan agama dan adat di Minangkabau.

Bentuk baju kurung yang dipakai oleh perempuan Minangkabau biasanya dihiasi oleh hasil kerajinan seperti: memakai tabur sulam benang emas dan sulam Suji Caia atau sulam Kapalo Samek (kepala peniti) dan bordir. Baju kurung biasanya dipakai dengan rok batik atau songket Pandai Sikek. Dalam karya ini baju kurung yang dibuat memakai hiasan kreasi sulaman Suji Caia dengan teknik kerancang dari benang emas/perak, ditata dengan pola hias yang mempunyai makna tentang sifat perempuan di Minangkabau.

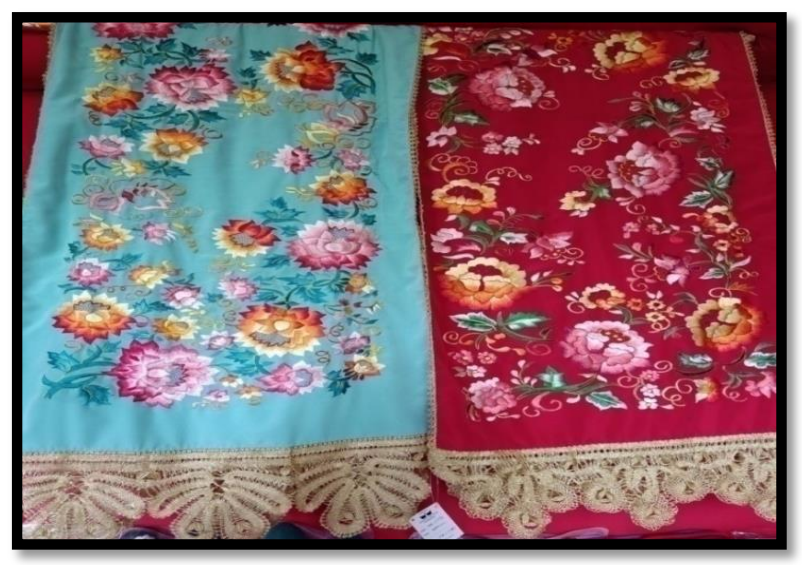

\section{Gambar 4}

Selendang Suji Caia Kotogadang Foto: Silva Yusalim, Oktober 2019

c) Tas

Tas digunakan untuk pergi baralek (acara pesta pernikahan), manjanguak (melayat) dan mando'a (acara syukuran). Dalam karya ini tas 
terbuat dari anyaman pandan dan bahan hitam yang dihiasi oleh Suji Caia dengan kain, dihiasi oleh kreasi Suji Caia kreasi kerancang timbul memakai benang menggunakan teknik kerancang timbul perak.

yang digunakan untuk meletakan barang Karya II

bawaan

\section{BENTUK KARYA SENI}

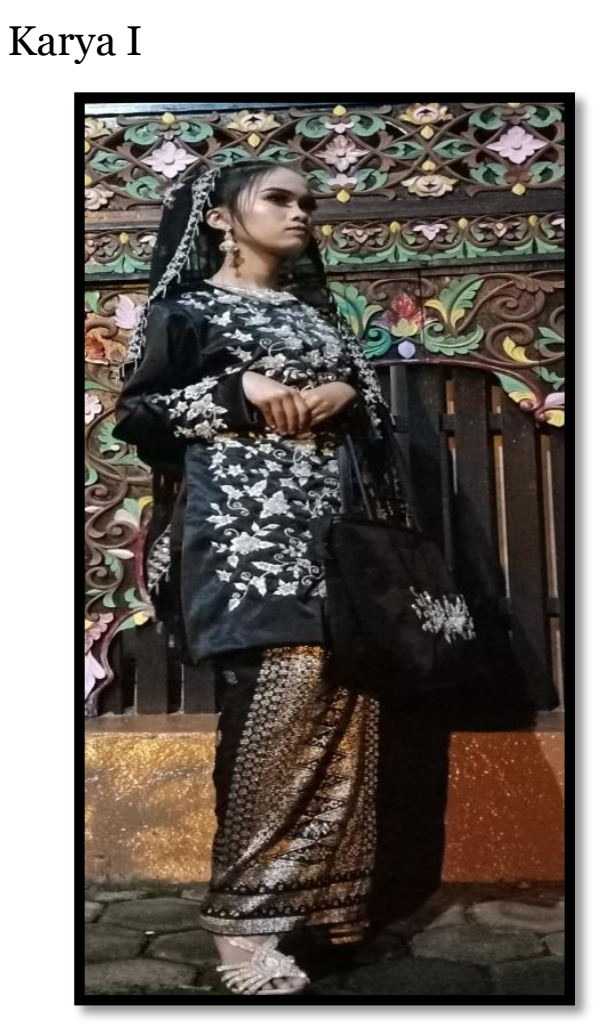

"Nan Gadang Basa Batuah" (Foto: Silva Yusalim, 2019)

\section{- Deskripsi Karya}

Karya yang berjudul "Nan Gadang Basa Batuah", dibuat pada tahun 2019 berbentuk pakaian perempan Minangkabau berpua kerudung, baju Galamai. Perpaduan warna dalam karya kurung dan tas menggunakan teknik Suji ini memakai bahan berwarna biru toska Caia dengan kreasi kerancang timbul yang dihiasi oleh Suji Caia dengan kreasi memakai benang perak metalik. Karya di kerancang timbul memakai benang atas dihiasi motif bunga Mawar dan motif berwarna kuning dan emas .

Minang Saik Galamai. Perpaduan warna

dalam karya ini memakai bahan berwarna

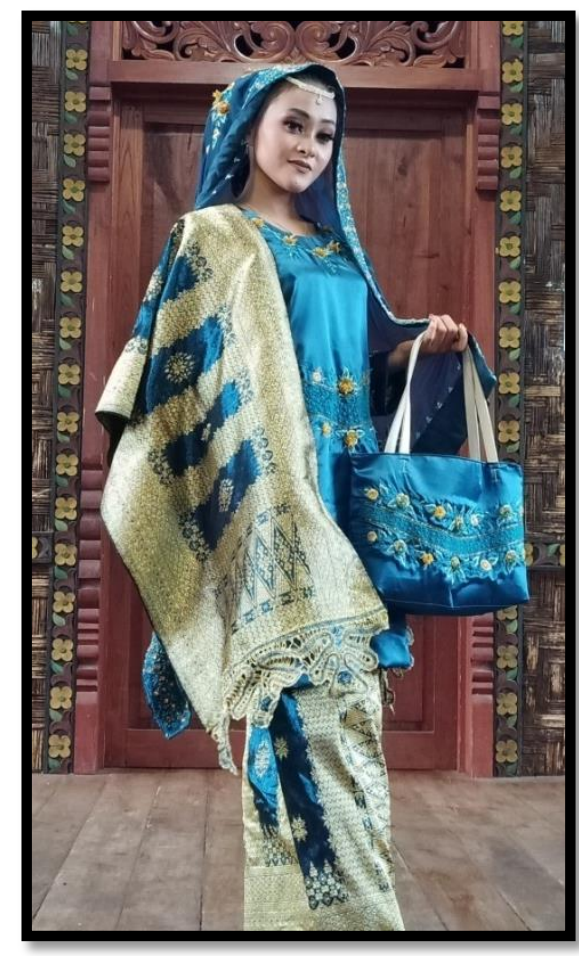

"Limpapeh"

(Foto: Silva Yusalim, 2020)

Karya yang berjudul "Limpapeh", dibuat pada tahun 2020 berbentuk pakaian perempan Minangkabau berupa kerudung, baju kurung dan tas menggunakan teknik Suji Caia dengan kreasi kerancang timbul memakai benang emas metalik. Karya di atas dihiasi motif bunga Mawar dan motif Minang Saik urwarna kuning dan emas. (1)

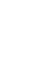




\section{PENUTUP}

Penciptaan karya seni "Kreasi Sulaman Suji Caia menggunakan Teknik Kerancang Timbul untuk Pakaian Perempuan Minangkabau" merupakan kolaborasi Suji Caia dengan kerancang manual berbentuk timbul menggunakan benang emas/ perak metalik. Kreasi Sulaman Suji Caia ini diterapkan pada pakaian perempuan Minangkabau berupa kerudung, baju kurung dan tas.

\section{DAFTAR PUSTAKA}

Akmal, Ahmad. 2013. Ekspresi Bentuk Simbolik Seni Ritual Makan Bajamba. Padang Panjang: Institut Seni Isi Padang Panjang.

Budiono. 2008. Kriya Tekstil. Jakarta:

Depertemen Pendidikan Nasional Dhavida, Usria, (1996). Pakaian Adat Wanita Payokumbuah. Padang:

Proyek Pembinaan Permuseuman Sumatera Barat.

Ernawati (2008). Tata Busana. Jakarta: Depdiknas.

Hakimy Idrus. 1994. Pegangan Penghulu,

Bundo Kanduang, Dan Pidato

Alua Pasambahan Adat Di

Minangkabau.Bandung: Remaja

Rosdakarya.

Jamil, Muhammad. 2015. Padusi Minang, Bukittinggi: Cinta Buku Agency.

Kartika, Dharsono Sony. 2004. Pengantar Estetika. Bandung:
Rekayasa Sains.

2016. Kreasi Artistik Perjumpaan Tradisi Modern Dalam Paradigma kekaryaan Seni. Surakarta: LPKBN Citra Sain. 2007. Kritik Seni. Bandung: Rekayasa Sains.

Mutia, Riza, dkk. (2012). Ragam Hias Koleksi Museum Adityawarman, Padang: Proyek Pembinaan Permuseuman Sumatera Barat.

Pulukandang, Wasia Roesbani. 2011. Menghias Kain, Bandung: Angkasa.

Razani, Sita Dewi, dkk. 2011. Sulam Tenun dan Renda Khas Kotogadang, Jakarta: Dian Rakyat.

Refisrul, dkk. 2012. Budaya Sumatra Barat, Padang: BPSNT Padang Press.

SP Gustami. 2007. Butir-Butir Mutiara Estetika Timur. Ide Dasar Penciptaan Seni Kriya Indonesia. Yogyakarta: Prasista.

Suhersono, Hery. 2004. Desain Bordir Flora dan Decoratif, Jakarta: PT GramediaPustaka Utama. 2005. Desain Bordir Motif Geometris. Jakarta: PT GramediaPustaka Utama. 2011. Bordir Lukis, Jakarta: Dian Rakyat

Soedjono, dkk. 2007. Membordir, 
Bandung: Angkasa.

Soedarso, Sp. 1974, Pengertian Seni, Terjemahan Buku The Meaning Of Art, Yogyakarta: STSRI.

Sumartono. 1992, "Orisinalitas Karya Seni

Rupa dan Pengakuan Internasional dalam SENI", Jurnal Pengetahuan dan Penciptaan Seni, II/o2, Yogyakarta BP ISI.

Surya, Dharma, 2011, Konsep Desain Dalam Pengembangan Produk,

Yuliarma. 2007. Perbaikan Proses Pembuatan Desain dan Teknik Hias Bordir serta Modifikasi Baju Tradisioanal Minangkbau Untuk Peningkatan Mutu dan diversifikasi Produk. Jakarta:Penelitian DP2M

-2009 Analisis Kreativitas Mahasiswa S1 Tata Busana Dalam Mendesain Warna pada Karyanya. Padang: UNP 